\title{
Human Factors Issues for Multi-Modular Reactor Units
}

\section{Joint $8^{\text {th }}$ IEEE HFPP $/ 13^{\text {th }}$ HPRCT}

Tuan Q. Tran

Humberto Garcia

Ronald L. Boring

Jeffrey C. Joe

Bruce P. Hallbert

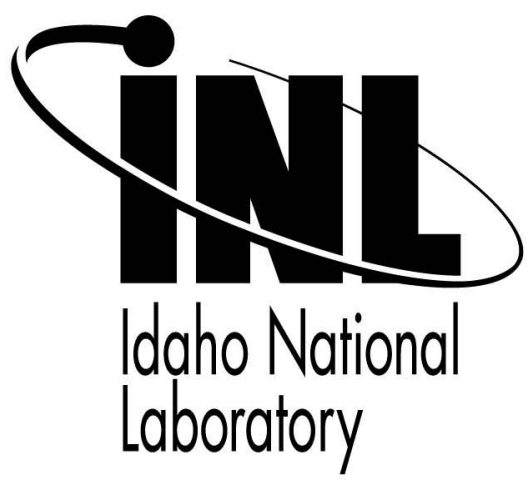

\section{August 2007}

This is a preprint of a paper intended for publication in a journal or proceedings. Since changes may be made before publication, this preprint should not be cited or reproduced without permission of the author. This document was prepared as an account of work sponsored by an agency of the United States Government. Neither the United States Government nor any agency thereof, or any of their employees, makes any warranty, expressed or implied, or assumes any legal liability or responsibility for any third party's use, or the results of such use, of any information, apparatus, product or process disclosed in this report, or represents that its use by such third party would not infringe privately owned rights. The views expressed in this paper are not necessarily those of the United States Government or the sponsoring agency. 


\title{
Human Factors Issues For Multi-Modular Reactor Units
}

\author{
Tuan Q. Tran, Humberto Garcia, Ronald L. Boring, \\ Jeffrey C. Joe, and Bruce P. Hallbert
}

Human Factors \& I\&C Systems Department, Idaho National Laboratory, Idaho Falls, ID. USA

Email: \{tuan.tran, humberto.garcia, ronald.boring, jeffrey.joe, bruce.hallbert \}@inl.gov

\begin{abstract}
Smaller and multi-modular reactors (MMR) will be highly technologically-advanced systems allowing more system flexibility to reactor configurations (e.g. addition/removal of reactor units). While the technical and financial advantages of such systems may be numerous, MMR presents many human factors challenges that may pose vulnerabilities to plant safety. An important human factors challenge in MMR operation and performance is the monitoring of data from multiple plants from centralized control rooms where human operators are responsible for interpreting, assessing, and responding to different system states (e.g., simultaneously monitoring refueling at one plant while vigilant to another plant's normal operating state). Furthermore, the operational, safety, and performance requirements for MMR can significantly change current staffing models and roles, the mode in which information is displayed, and the approach for conducting procedures and training. Consequently, addressing human factors concerns in MMR is essential in reducing plant risk.
\end{abstract}

\section{INTRODUCTION}

An important human factors challenge in MMR operation and performance is the monitoring of data from multiple plants from centralized control rooms where human operators are responsible for monitoring, detecting, interpreting, assessing, and responding to system's states and anomalies. MMR will be more computerized, intelligent, integrated, and automated, thus shifting the operator's role to more of a supervisory control with emphasis on monitoring, possibly under high task-load. High task-load is known to induce stress as well as fatigue, with vigilance dropping drastically after $30 \mathrm{~min}$ of prolonged monitoring. Interactively, these factors can severely diminish one's ability to perceive, recognize, and respond to emergency or unanticipated events and, thus, can place both the operator and system at risk. Furthermore, the operational, safety, and performance requirements for MMR can seriously change the current staffing models and roles, the mode in which information is displayed, and the approach for conducting procedures and training. For these reasons, addressing human factors concerns in MMR is essential in reducing plant risk.

\section{HUMAN FACTORS CONCERNS}

\section{A. Staffing Model}

Staffing is an important concern in any plant modernization but more so when the plant becomes highly automated and modularized. Increases in plant automation will lead to a reduction in staff personnel and make obsolete the traditional staffing model of onsite staff crew for one reactor [1], thus significantly reducing operation and maintenance (O\&M) costs. Automated multi-modular systems will be more likely to incorporate a reduced staff model of:

- An onsite individual for one reactor,

- An onsite individual for multiple reactors, or

- Decentralized groups with offsite specialists (that are called when a disturbance occurs)

While an increase in automation portrays an advantage of reducing the staffing model during normal operating procedures, it is uncertain whether such a staff model will be as effective during unanticipated events (e.g., software failures) or densely traffic situation (e.g., recovery from an initiating event). Reference [2] warns of this illusion of automation referred as "clumsy automation", in which automation tends to make human tasks easy during normal operation but can also make them harder during unanticipating events.

Staff roles (i.e., responsibilities, skills, and knowledge to perform assigned tasks and functions) will also need to be redefined with an increase in automation and changing of the staff model [1]. For example, the responsibility of overseeing plant operations can be reallocated from a senior human operator to an intelligent monitoring system. Accordingly, such highly automated systems would necessarily need highly qualified operators with a strong technical background to oversee operations. Lastly, with a reduced staff and more complex systems come a need for greater team cognition (e.g., shared similar mental model/situation awareness) and team cohesion (i.e., work-well together), particularly during high traffic or stressful situations. For example, communication errors can arise between crew members who do not share a similar frame of reference (i.e., situation awareness).

\section{B. Human-System Interface (HSI) and Automation}

Responsibilities for human operators in a highly automated multi-modular system will primarily be monitoring (i.e., checking the system status) and detecting (i.e., recognizing that something is not operating normally in the system). In addition, these actions may need to be performed in the context of information overload or complexity (e.g., simultaneously monitoring the status of multiple 
reactors). It is well-known that humans are poor monitors of automated systems [3] arguably because automation induces passive monitoring and disengagement (e.g, when attention is directed somewhere else) leading to poor situation awareness [2]. Because of this, successful and reliable human performance relies heavily on HSI design [4]. HSI design needs to address the following human factors concerns: how information is accessed with automation, how resources are shared, how complex information should be presented, how operators would control multiple modules, and how automation affects on human functional states.

In a highly automated system, the designer needs to distinguish what information is best pushed (i.e., displayed without the operator initiative), what information is best pulled (i.e., operator would need to specifically request it), what information should be denied and to whom, and how should information be prioritized [3]. Furthermore, the HSI designer needs to address shared resources (i.e., "who has the ball") during emergency situations: who will make the operational decision, what is the consequence of bypassing or overriding the automated system, and should operator need to meet a certain qualification to override the automated system [1]. The more complex or ambiguous the information the more likely human errors will occur because of high workload or loss of situation awareness. For example, an interface that demands a prolonged period of monitoring can severely decrease an operator's vigilance or an interface that does not present complex information in a simple and easy to understand fashion can cause the operator to create an ill-constructed "mental model" leading to poor situation awareness. Thus, it is critical that information is presented within the human perceptual and cognitive limitations. Finally, the HSI designer also needs to determine how operators are expected to search and scan through multi-functional display (e.g., windows for different reactor's mode of operation or information) monitoring MMR. For example, if using soft keys, then how many functions can be mapped into any one key? If hidden keys are used, will operators be able to accurately search and locate them during time of high stress?

In addition to HSI, automation can have a severe effect on human skills. For example, less manual activities by the operator are required in an automated system. As a result, operator knowledge and skills can begin to deteriorate due to infrequent use. This can be problematic when the system is quickly switched from normal operation mode to an emergency mode. Problem-solving activities may become slower because it may take longer for the operator to retrieve the necessary information from memory (i.e., speed of memory retrieval is related to information frequency of use) $[5,6]$. Thus, the HSI designer needs to assess whether periodic refresher training exercises or embedding critical information within the system with pointers for operators to quickly access can mitigate this deteriorating effect on human skills. Lastly, automation can elicit a feeling of false security. That is, overly trusting the system (i.e., over-reliance on system indicators) to portray accurate information and perform correct actions [5]. This matter of overly trusting an automated system was one of the root causes of the 2003 Northeast Blackout, leaving a major portion of the northeastern United States and the Ontario area of Canada without power for over 24 hours. Although the initial event of the blackout was due to unkempt trees hitting power lines in Ohio, the problem was worsened by the fact that First Energy's computerized alarm system failed silently and operators were relying on outdated information, overly trusting their systems, and disregarding phone calls alerting them about their worsening condition on their grid [7].

\section{Procedures and Training}

Important concerns with any plant modernization are procedures and training. As discussed earlier, highly automated systems will require operators to have more technical skills and knowledge of the system. Thus, it is important that personnel receive adequate training and get accustomed to different procedures. Such procedures and training will need to be defined for the new or modernized systems [1]. Typically, industry has used the traditional classroom learning approach in which the learner passively absorbs information transmitted via a verbal lecture, powerpoint presentation, film, video, textbook readings, and/or online manuals. Such learning approaches have been criticized as superficial. This criticism is based on a fundamental principle in human learning and memory that information that induces more active engagement leads to better learning outcomes [8]. Thus, some educators have endorsed more engaging learning approaches such as case-based learning [8]. Case-based learning approach involves presenting students with case studies or scenarios that describe a fictitious or real event. After reading the case study, students then apply principles that they have learned to resolve the case, usually through instructor-facilitated group discussion. The case-based learning approach is believed to be effective because it depicts the complexity and uncertainty of real world events in its problem-solving scenario [8]. However, it is uncertain how effective a case-based learning approach is in the context of procedural skill learning. In the end, an effective learning approach must encompass at least the following characteristics:

- Promote a steep learning curve, 
- Improve resistance to negative transfer (i.e., interference of new skills by previous learned skills)

- Be cost-effective.

Other relevant issues that designers must address include the recruitment of highly skilled operators, whether a partial-training schedule should be use, and how often a refresher training session should be given.

\section{Risk Analysis}

An irony of automation is that while the intention of automation is to lessen operator's workload and stress, increase in automation tends to lead into an increase in system complexity [9]. Thus, the complexity of a multimodular system will make human risk more difficult to identify. In a complex system, risk can migrate (i.e., solving one problem may introduce another somewhere else in the system) and lay dormant (i.e., latent risk) for a long period of time [5]. Thus, as the system complexity gets higher, the need of human reliability analysis (HRA) is more critical. Reference [10] noted that the goals of human reliability analysis are "to render a complete description of the human contribution to risk and to identify ways to reduce that risk" (p.2). With MMR systems, HRA analysts need to address which HRA methods to use, whether standard HRA methods can be used in a setting where many operational details are still unknown, and whether current standardized plant risk estimates can be accurately generalized to a MMR system.

\section{Operator's Functional State}

Reference [5] characterized nuclear power plant operator's environment as "hours of intolerable boredom punctuated by a few minutes of pure hell" ( $p$. 508). Thus, illustrating a roller-coaster of emotion, an operator is confronted with boredom and fatigue during normal operation and high levels of stress and uncertainty during system malfunctions. Cognitively, an operator's vigilance dramatically drops after 30 minutes of prolonged monitoring. Moreover, simultaneously observing multiple modules can increase workload leads to "ill-constructed" situation awareness or mode errors [2] in which the operator fails to recognize mode transitions of different plant states (e.g., refueling and start-up). It is believed this problem will magnify with increases in automation and system complexity. For this reason, assessing the operator's functional state is essential to reduce plant risk. For example, after identifying the moment an operator is experiencing a high level of fatigue, the operator can be directed to take a break by his/her supervisor. What needs to be addressed is how to reliably assess the operator's functional state. More specifically, what methods should be used (e.g., eye-tracking, posturing techniques, behavioral inputs, such as keystroke, or physiological measures, such as EEG), how to define degraded performance, and what to do when an operator's performance is degraded (e.g., allow automated system to slow down information flow or operator should be given a warning message that their performance has dropped).

\section{E. Section I. Summary}

In summary, MMR presents many human factors challenges that must be alleviated for efficient and safe human performance in control rooms. We highlighted several key human factors issues that will be impacted with the implementation of a newly advance automated MMR, specifically:

- Current standardized staffing model and roles will become obsolete

- Information displays will need to be re-configured to present complex information as well as redefining shared resources between the automated system and the human operators

- The averse influence of automation on operator's skills, knowledge, trust will have to be addressed

- New training and qualifications will need to be redefined

- Human reliability analysis will need to be conducted

- Operator's functional state in a highly automated system will need to be monitored and assessed

We next discuss some traditional human factors approaches to address the above human factors concerns.

\section{HUMAN FACTORS APPROACHES IN ASSISTING PLANT MODERNIZATION}

\section{A. Guidelines and Operating Experience Review}

Reviewing current guidelines and operating experience are a good starting point to address the numerous human factors concerns presented earlier. Human factors guidelines are important to ensure that accepted human principles and practices are implemented in the design process as well as to provide criteria for evaluating design principles that have already been incorporated into the system [11]. This approach rests upon the assumption that new reactor systems share some overlapping features of their predecessor systems. In this way, validated principles and practices can be roughly generalized to new plants. For example, NUREG/CR-6838 [12] discusses U.S. Nuclear Regulatory Commission (NRC) regulations and regulatory guidance related to staffing levels and staffing design (See Table 1). The designer can initially 
use the recommended number of staff to power units and adjust accordingly with operational experience.

Other guidelines can be found in:

- The Standard Review Plan [13]

- Human Factors Engineering Program Review Model [14]

- Human-System Interface Design Review Guideline [15]

- Human-System Interface and Plant Modernization Process: Technical Basis and Human Factors Review Guidance [16]

- Technical Basis for Regulatory Guidance for Assessing Exemption Requests from the Nuclear Power Plant Licensed Operator staffing Requirements Specified in 10 CFR 50.54(m) [17]

TABLE 1. STAFFING OF NUCLEAR POWER UNITS BY OPERATOR AND SENIOR OPERATORS LICENSED UNDER 10 CFR PART 55 (TAKEN FROM REFERENCE [12])

\begin{tabular}{|c|c|c|c|c|c|}
\hline \multirow{2}{*}{} & $\begin{array}{c}\text { One } \\
\text { Units }\end{array}$ & \multicolumn{2}{|c|}{ Two Units } & \multicolumn{2}{c|}{ Three Units } \\
\cline { 2 - 6 } Position & $\begin{array}{c}\text { One } \\
\text { Control } \\
\text { Room }\end{array}$ & $\begin{array}{c}\text { One } \\
\text { Control } \\
\text { Room }\end{array}$ & $\begin{array}{c}\text { Two } \\
\text { Control } \\
\text { Room }\end{array}$ & $\begin{array}{c}\text { One } \\
\text { Control } \\
\text { Room }\end{array}$ & $\begin{array}{c}\text { Two } \\
\text { Control } \\
\text { Room }\end{array}$ \\
\hline $\begin{array}{c}\text { Senior } \\
\text { Operator }\end{array}$ & 1 & 1 & 1 & 1 & 1 \\
\hline Operator & 1 & 2 & 2 & 3 & 3 \\
\hline $\begin{array}{c}\text { Senior } \\
\text { Operator }\end{array}$ & 2 & 2 & 2 & 2 & 2 \\
\hline Operator & 2 & 3 & 3 & 4 & 4 \\
\hline $\begin{array}{c}\text { Senior } \\
\text { Operator }\end{array}$ & & 2 & 3 & 3 & 3 \\
\hline Operator & & 3 & 4 & 5 & 5 \\
\hline $\begin{array}{c}\text { Senior } \\
\text { Operator }\end{array}$ & & & & 3 & 4 \\
\hline Operator & & & & 5 & 6 \\
\hline
\end{tabular}

In addition to using well-established guidelines, operating experience reviews (e.g., lessons learned) can be used to mitigate past negative features, while retaining positive features of predecessor systems. These operating experience reviews can be used to roughly assess the initial staffing demands of a multimodular system and to revise them accordingly. The strengths of this approach are that it requires no special equipment, guidelines are endorsed by the NRC, and can be completed in a relatively short time. The weaknesses are that the guidelines may not be a complete fit with the new system, and will need some revisions, and in some instances, guidelines may be obsolete within the new system. As Rasmussen and Goodstein (1988, p. 179, cited in [11]) commented, "Introduction of new technology, as illustrated by the on-march of advance information systems destroys the blanket of established know-how and practice..." Consequently, it is important to understand the task characteristics either through a detailed and systematic analysis of the task or through eliciting experts' opinions.

\section{B. Task Analysis And Expert's Judgments}

Task analysis is the process of specifying the functional steps and operator's skills and knowledge that are needed to accomplish a task. A task is a group of activities that have a common objective goal [12]. A task analysis can be used to determine the staff model, staff roles, training needs, or whether the newly designed interface fits within the limits of human performance (e.g., attention and workload.). For example, to determine the staff model, a task analysis can be performed on the different types of tasks that the crew will need to perform as well as the requirements to accomplish the task. After the task analysis has been conducted, the results can be given to a group of experts assembled from various areas (such as control room, reactor system, and turbine system design and operations) to discuss, assess, and agree upon the "bestfit" for the staffing model, personnel qualifications, training, and procedure requirements, and the quality of the newly designed interface [18].

In cases where the operating task is still unknown or ill-defined, analysts can interview experts with significant operating experiences to seek their input of how the task's characteristics will likely be defined. Based on expert's judgment, a task analysis can be performed. Expert elicitation can be tricky. Analysts must be conscious of any biases that he/she may have in framing questions to experts. Because of this, it is advised that analysts follow standardized guidelines in eliciting expert's opinion [18]. The strengths of this approach are that it requires no special equipment and can be completed in a relatively short period. The weaknesses are that this approach is very subjective, discussion can be dominated by certain members, and experts can be difficult to assemble [18].

\section{Human Reliability Analysis (HRA)}

As system complexity increases, the need for risk analysis becomes more important. Human reliability analysis allows an in-depth focus on identifying, qualifying, and quantifying human errors contribution to system risk. The goal of identification is merely considering what tasks the human operator is likely to fail or commit an error. Such identification can be based upon empirical findings, interviews, observation, written documents (e.g., operational experience review), and expert judgments. Once a likelihood failure event is identified, the qualification phase consists of decomposing the event into sub-tasks in the form of probabilistic risk assessment's event trees or fault trees (similar to task-analysis). Each branch in the event or fault tress symbolizes, in terms of probabilities, a 
correct or failure response by the human. The branches are then quantified to obtain an overall human error probability rate for an event. The strength of this approach is that it is heavily based on task analysis. Consequently, HRA can be used in a variety of tasks, as long as a task can be decomposed. The weakness of this approach is that many of its probability estimates used to calculate human error rates is based on scarce empirically-based research thus, relying heavily on expert's judgment [10].

\section{Experiments/Simulator}

Simulator experiments allow a controlled and realistic investigation of many human factors concerns. Simulator experiments can be used to verify conclusions offered by other approaches, such as guidelines or task analysis/expert's judgment. For example, let's say that task analysis and expert's judgment concluded Interface A, an operator can monitor three reactor systems with minimum cost to performance, whereas monitoring three reactor systems through Interface B will have a detrimental effect on performance. To test this conclusion, a certain number of operators can be randomly assigned to Interface A while the remaining operators be assigned to Interface B. Within each interface condition, operators can be asked to monitor 1 , 2, 3, or 4 reactors. Number of hits (correctly identification of) and misses (number of mis-identified problems) can be used as performance measure. As illustrated in Figure 1, the results of the experiment may show that both Interface A and B support good performance when the operators are asked to monitor 1 reactor.

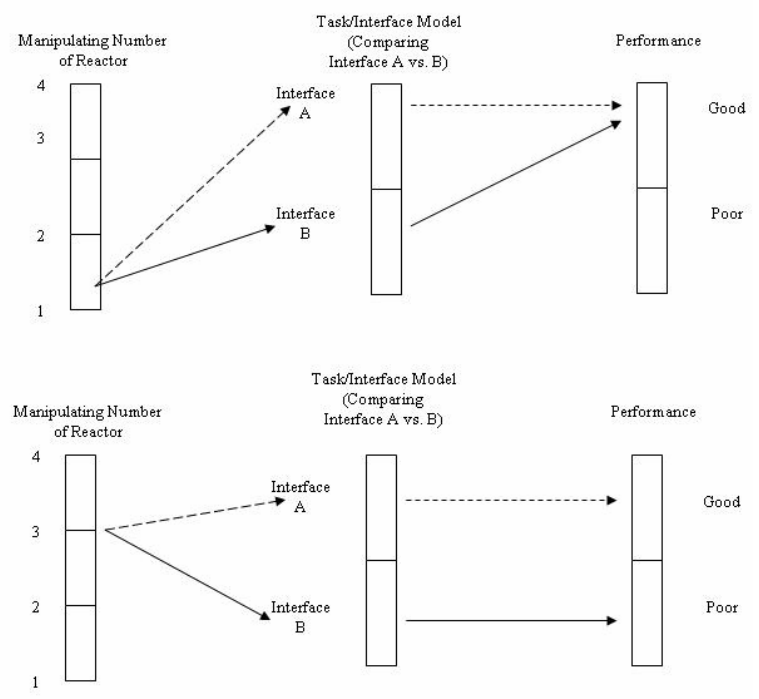

Figure 1. Simulator experiment predicted results
Conversely, when the number of reactors needing monitoring increases to three reactors, Interface B leads to detrimental performances. The strength of this approach is its high validity and flexibility. The weakness is that it requires highly trained operators and can be very costly [1].

\section{E. Human Performance Modeling (HPM)}

Human Performance Modeling (HPM) estimates or simulates human performance over time based upon engineering and psychological models of human performance. Typically, HPM requires data reflecting the task properties (e.g., details of the task, task sequence, and time needed to complete the task), environmental conditions, and algorithms to represent performance variations of the human operator. With these parameters, HPM can run thousands of simulated trials (akin to Monte Carlo) of overall system performance under different contexts or "what if" scenarios in a very short time. Problems can be identified and resolved very early in the design process before a design prototype is constructed. Thus, using HPM early in the design process can be very costeffective [19]. The strengths of this approach are that it allows easy exploration of new scenarios costeffectively, and offers a more rigorous analysis compared to other approaches (e.g., task analysis/expert's judgments). The weaknesses with HPM are that validity is not as good as an experiment and that developing HPM requires programming skills.

\section{CONCLUSIONS}

Table 2 summarizes the strengths and weaknesses of each human factor approaches that were discussed in this paper.

TABLE 2. SUMMARY OF STRENGTHS AND WEAKNESSES OF

\begin{tabular}{|l|l|l|}
\multicolumn{2}{|c|}{ EACH HUMAN FACTORS APPROACHES } \\
\hline Resources & Strengths & Weaknesses \\
\hline $\begin{array}{l}\text { Guidelines \& } \\
\text { Operating } \\
\text { Experience Review }\end{array}$ & $\begin{array}{l}\text { Requires no special } \\
\text { equipments \& } \\
\text { relatively quick to } \\
\text { complete }\end{array}$ & $\begin{array}{l}\text { Guidelines may not } \\
\text { completely fit with } \\
\text { new system or } \\
\text { obsolete within new } \\
\text { system }\end{array}$ \\
\hline $\begin{array}{l}\text { Task Analysis \& } \\
\text { Expert's Judgment }\end{array}$ & $\begin{array}{l}\text { Requires no special } \\
\text { equipments \& } \\
\text { relatively quick to } \\
\text { complete }\end{array}$ & $\begin{array}{l}\text { Very subjective \& } \\
\text { may be difficult to } \\
\text { assemble experts }\end{array}$ \\
\hline $\begin{array}{l}\text { Experiment \& } \\
\text { Simulations }\end{array}$ & $\begin{array}{l}\text { High validity \& } \\
\text { flexibility }\end{array}$ & $\begin{array}{l}\text { Requires trained } \\
\text { operators \& very } \\
\text { costly }\end{array}$ \\
\hline $\begin{array}{l}\text { Human } \\
\text { Performance } \\
\text { Modeling }\end{array}$ & $\begin{array}{l}\text { Easy exploration of } \\
\text { new scenarios, cost- } \\
\text { effective, and } \\
\text { rigorous analysis }\end{array}$ & $\begin{array}{l}\text { Requires } \\
\text { programming skills } \\
\text { \& validity is not as } \\
\text { high as an } \\
\text { experiment }\end{array}$ \\
\hline
\end{tabular}

MMR systems will be more complex and automated leading to many human factors concerns that must be 
addressed before the full benefits of such systems can be realized. In this paper, we highlighted some of the human factors concerns and human factors approaches for MMR system designers.

\section{DISCLAIMER}

This paper was prepared as an account of work sponsored by an agency of the United States Government. Neither the United States Government nor any agency thereof, nor any of their employees, makes any warranty, expressed or implied, or assumes any legal liability or responsibility for any third party's use, or the results of such use, of any information, apparatus, product, or process disclosed in this paper, or represents that its use by such third party would not infringe privately owned rights.

\section{REFERENCES}

[1] Bley, D., DeBor, J., Eckenrode, R., Hallbert, B., Holmstrom, C., Hugo, J., O’Hara, J., Persensky, J. Human system interactions. In D.W. Miller, E.L. Quinn, S.A. Arndt, L.J. Bond, D.B. Jarrell, J.M. O'Hara, and R.T. Wood (Eds.), Instrumentation, Controls, and Human-Machine Interface Technology Workshop, Gaitherburg, MD, 2002.

[2] Lee, J.D. Human factors and ergonomics in automation design. In G. Salvendy (Eds.), Handbook of Human Factors and Ergonomics $3^{\text {rd }}$ Ed., New Jersey: John Wiley \& Sons, Inc, 2006, pp. 1570-1596.

[3] Abbott, K., Corker, K., Figarol, S., Hoekstra, J., Pritchett, A., \& Sheridan, T. Panel on human-automation interaction in the next generation air transportation system. Proceedings of the International Conference on Human-Computer Interaction in Aeronautics, 2006, pp. 246-247.

[4] Xing, J. Developing metrics of information complexity for automation displays. Proceedings of the International Conference on Human-Computer Interaction in Aeronautics, 2006, pp. 177-184.

[5] Wickens, C. Engineering psychology and human performance $2^{\text {nd }}$ Edition. New York: HarperCollins Publishers Inc, 1992.

[6] Wickens, C., \& Kessel, C. Failure detection in dynamic systems. In J. Rasmussen and W.B. Rouse (Eds.), Human Detection and Diagnosis of System Failures. New York: Plenum Press, 1981, pp. 155-169.

[7] U.S.-Canada Power System Outage Task Force. Interim Report: Causes of the August $14^{\text {th }}$ blackout in the United States and Canada, 2003.

[8] Schank, R. Inside multi-media case based instruction. New York: Lawrence Erlbaum Associates, 1998.

[9] Amelink, M., Mulder, M., van Paassen, R., Lintern, G., \& Solodilova-Whiteley. Proceedings of the International Conference on Human-Computer Interaction in Aeronautics, 2006, pp. 160-163

[10] Gertman, D.I., \& Blackman, H.S. Human Reliability and Safety Analysis Data Handbook. New York: John Wiley \& Sons, Inc., 1994.

[11] Stubler, W., O'Hara, J., Higgins, J., and Kramer, J. HumanSystem Interface and PlantModernization Process: Technical Basis and Human Factors Review Guidance (NUREG/CR6637). Washington, DC: U.S. Nuclear Regulatory Commission, 2000 .

[12] Plott, C., Engh, T., \& V. Barnes. Technical basis for regulatory guidance for assessing exemption requrests from the nuclear power plant licensed operator staffing requirements specified in
10 CFR 50.54(m) (NUREG/CR-6838). Washington, DC: U.S. Nuclear Regulatory Commission, 2004.

[13] US Nuclear Regulatory Commission. Standard review plan for the review of safety analysis reports for nuclear power plants (NUREG-0800). Washington, DC: U.S. Nuclear Regulatory Commission, 2007. (Obtain at http://www.nrc.gov/reading$\mathrm{rm} /$ doc-collections/nuregs/staff/sr0800/)

[14] O’Hara, J.M., Higgins, J.C., Persensky, J.J., Lewis, P.M., \& Bongarra, J.P. Human factors engineering program review model (NUREG-0711, Rev 2). Washington, DC: U.S. Nuclear Regulatory Commission, 2004.

[15] O'Hara, J.M., Brown, W.S., Lewis, P.M., \& Persensky, J.J. Human-system interface design review guidelines (NUREG0700, Rev 2). Washington, DC: U.S. Nuclear Regulatory Commission, 2002.

[16] Stubler, W.F., O’Hara, J.M., \& Higgins, J.C. Human-system interface and plant modernization process: Technical basis and human factors review guidance (NUREG/CR-6637). Washington, DC: U.S. Nuclear Regulatory Commission, 2000.

[17] O’Hara, J.M., Higgins, J.C., Persensky, J.J., Lewis, P.M., \& Bongarra, J.P. Human factors engineering program review model (NUREG-0711, Rev. 2). Washington, DC: U.S. Nuclear Regulatory Commission, 2004.

[18] Boring, R., Gertman, D., Joe, J., Marble, J., Galyean, W., Blackwood, L., \& Blackman, H. Simplified expert elicitation guideline for risk assessment of operating events (INL/EXT-0500433). Washington, DC: U.S. Nuclear Regulatory Commission, 2005.

[19] Gore, B.F., \& Jarvis, P.A. New integrated modeling capabilities: MIDAS' recent Behavioral Enhancements. Proceedings of the 2005 Aerospace Congress, 2005, 2005-01-2701. 